\title{
O XANGÔ NA SALA de AuLA: DILEMAS DA IDENTIDADE RELIGIOSA AFRO-BRASILEIRA EM ALAGOAS
}

\author{
THE XANGÔ IN THE CLASSROOM: \\ DILEMMAS OF AFRO-BRAZILIAN RELIGIOUS IDENTITY IN ALAGOAS
}

\author{
Amurabi Pereira de Oliveira ${ }^{(*)}$ \\ KLEVERTON ARTHUR DE Almirante ${ }^{(*)}$ \\ FERNANDA NASCIMENTO DOS SANTOS ${ }^{(* *)}$
}

\begin{abstract}
RESUMO
Neste artigo buscamos analisar a relação entre identidade religiosa e a escola, mais especificamente entre a identidade religiosa afro-brasileira no estado de Alagoas. Partimos de duas pesquisas para realizar nossas reflexões, uma envolvendo as crianças de candomblé no espaço escolar, que está sendo realizada em Maceió, capital de Alagoas, e outra acerca do ensino religioso no município de Messias, região metropolitana de Maceió. Acreditamos que ocorre um processo de invisibilização da identidade religiosa afro-brasileira no espaço escolar, e que só pode ser compreendido ao considerarmos o contexto histórico do candomblé, ou Xangô, no Brasil e em Alagoas. Estas questões apontam para o caráter monocultural da escola, ainda que devamos reconhecer as mudanças em cursos, apontadas principalmente pelo avanço do aparato legal em torno das questões étnico-raciais em educação.

Palavras-Chave: Religiões Afro-brasileiras. Escola e Cultura. Identidade Religiosa. Religião e Espaço Público.
\end{abstract}

\begin{abstract}
In this paper we analyze the relationship between religious identity and the school, more specifically between afro-brazilian religious identity in the state of Alagoas. We do it from two surveys to conduct our reflections, one involving the children of Candomble in the school, which is being held in Maceió, capital of Alagoas, and another about religious education in the city of Messias, the metropolitan area of Maceió. We believe that there is a process of invisibilization of afro-brazilian religious identity in the school, and that this can only be understood when we consider the historical context of Candomblé, or Xangô, in Brazil and Alagoas. These issues point to the character monocultural school, although we should acknowledge changes in courses, aimed primarily at advancing the legal apparatus around ethnic and racial issues in education.

KEYWORDS: Afro-Brazilian Religions. School and Culture. Religious Identity. Religion and Public Space.

INTRODUÇÃO

A escola, como a conhecemos atualmente, é fruto de um longo processo de formação sociocultural marcado por intensas disputas entre concepções de
\end{abstract}

(*) Doutor em Sociologia pela Universidade Federal de Pernambuco (2011). Professor do Programa de PósGraduação em Educação da Universidade Federal de Alagoas -UFAL. Atua principalmente nos seguintes temas: Religiosidade, Nova Era, Novos Movimentos Religiosos, Vale do Amanhecer, Sociologia e Antropologia da Educação. E-mail: amurabi_cs@hotmail.com.

${ }^{(* *)}$ Mestrando em Educação pela Universidade Federal de Alagoas. Bolsista da Fundação de Amparo à Pesquisa do Estado de Alagoas - FAPEAL.

${ }^{(* *)}$ Licenciada em Pedagogia pela Universidade Federal de Alagoas. 
sociedades divergentes (PETITAT, 1994). Em seu processo de constituição, uma das marcas mais fortemente estabelecidas refere-se à intima relação entre escola e cultura, que se coloca historicamente em contínua tensão.

Os estudos de Bourdieu e Passeron (2008) apontaram como a cultura ocupa um lugar central no processo de exclusão social, operacionalizado na escola e presente na sociedade capitalista moderna. Não que a escola simplesmente reproduza as relações sociais, aprofundando as desigualdades, contudo contribui para esse processo.

O cenário se torna ainda mais complexo com a emergência da questão do multiculturalismo nas sociedades contemporâneas. Como indica Hall (2009), trata-se de vários "tipos" de multiculturalismo, uma vez que o multiculturalismo deve ser entendido como uma forma de lidar com a realidade multicultural, e não apenas um dado evidente e permeado pelas relações de poder que se estabelecem nas diversas camadas sociais.

No caso da sociedade brasileira, a questão das diversidades social e cultural sempre se mostrou desafiadora, tornando-se ainda mais visível na passagem do século XIX para o XX, quando ocorreu o processo de abolição formal da escravidão no país, bem como uma rápida industrialização nos grandes centros, que implicou no deslocamento de agrupamentos humanos do espaço do rural para as cidades. Neste cenário, o "outro" aproxima-se da escola e se torna um problema político a ser encarado (FREITAS, 2005).

Considerando o cenário atual da educação no Brasil, fazem-se relevantes as colocações de Moreira e Candau (2003, p. 160), ao indicarem que:

[...] numerosos estudos e pesquisas têm evidenciado como essa perspectiva termina por veicular uma visão homogênea e padronizada dos conteúdos e dos sujeitos presentes no processo educacional, assumindo uma visão monocultural da educação e, particularmente, da cultura escolar. Essa nos parece ser uma problemática cada vez mais evidente. O que está em questão, portanto, é a visão monocultural da educação. Os "outros", os "diferentes" - os de origem popular, os afrodescendentes, os pertencentes aos povos originários, os rappers,os funkeiros etc. , mesmo quando fracassam e são excluídos, ao penetrarem no universo escolar desestabilizam sua lógica e instalam outra realidade sociocultural.

Essa nova configuração das escolas expressa-se em diferentes manifestações de mal-estar, em tensões e conflitos denunciados tanto por educadores(as) como por estudantes. É o próprio horizonte utópico da escola que entra em questão: os desafios do mundo atual denunciam a fragilidade e a insuficiência dos ideais "modernos" e passam a exigir e suscitar novas interrogações e buscas. A escola, nesse contexto, mais que a transmissora da cultura, da "verdadeira cultura", passa a ser concebida como um espaço de cruzamento, conflitos e diálogo entre diferentes culturas. 
Evidentemente as tensões estabelecidas no espaço escolar variam de acordo com os grupos envolvidos e com o contexto social, político e histórico determinado. Buscaremos analisar nesse breve trabalho a questão da identidade religiosa afro-brasileira no espaço escolar em Alagoas, tomando como ponto de partida a análise dos dados oriundos de duas pesquisas etnográficas: uma envolvendo o Ensino Religioso no município de Messias, região metropolitana de Maceió, e outra sobre a identidade de crianças praticantes de Candomblé no espaço escolar.

\section{As PESQUiSAS ${ }^{1}$}

\section{CRIANÇAS CANDOMBLECISTAS}

De acordo com Graue e Walsh (2003, p. 122), “existem grupos de crianças acerca das quais a sociedade pouco conhece, necessitando por isso de aprofundar”. Neste sentido, as pesquisas com as crianças de Candomblé se fazem extremamente importantes para a contribuição aos estudos sobre as relações étnico-raciais e o multi/interculturalismo no ambiente escolar.

No presente artigo, a mostra dos resultados preliminares sobre as crianças de Candomblé, de 9 e 12 anos de idade, fazem parte de uma pesquisa de Mestrado em andamento que, no momento, como fruto das primeiras incursões em campo, esteve a visar a discussão sobre os processos de aprendizagem vivenciados por estas crianças no terreiro e que concepções elas têm formuladas sobre a escola, além de se propor a saber como articulam o que é vivenciado nestes dois espaços de aprendizagens.

$\mathrm{O}$ foco desse trabalho remeteu-se às observações realizadas no espaço do terreiro, utilizando-se para tanto de observações de campo, conversas informais e realização de algumas entrevistas.

O trabalho mostrou-se complexo por dois motivos. Primeiramente, o investigador ao deixar de ser criança e se tornar adulto esquece-se de como é ser criança, tendo suas inferências sobre o universo das mesmas como algo etnocêntrico e temporal, necessitando da investigação etnográfica para entender como se dão as relações culturais das crianças do grupo estudado. Como apontam Graue e Walsh (2003, p. 115), a investigação com crianças deve ser considerada como "um modo disciplinado e sistemático de conviver com crianças que sabem mais do seu mundo que o investigador".

\footnotetext{
${ }^{1}$ Apesar de nos utilizarmos aqui dos dados obtidos por meio de duas pesquisas etnográficas não se trata, em absoluto, de produzir um texto etnográfico no sentido mais estrito do termo, mas sim, a partir dessas pesquisas, em diálogo com a literatura pertinente neste campo de investigação, elaborar uma reflexão em torno dos dilemas das identidades afro-brasileiras no espaço escolar em Alagoas.
} 
Em segundo lugar, foi preciso buscar por "[...] tirar a capa de membro de uma classe e de um grupo social específico para poder - como etnólogo estranhar alguma regra social familiar e assim descobrir (ou recolocar, como fazem as crianças quando perguntam os "porquês") o exótico no que está petrificado dentro de nós pela reificação e pelos mecanismos de legitimação" (DAmATTA, 1978, p. 28-29), pois um dos autores do artigo fruto da pesquisa inicial faz parte do universo do terreiro como membro religioso.

Coube a tentativa, na imersão como pesquisador em um universo do qual se faz parte, de se livrar de um empirismo ingênuo que poderia apontar para um processo simples, sem grandes entraves para o desenvolvimento da investigação - como os problemas de pesquisa, perguntas e descobertas. Para se chegar a este ponto de partida, a revisão bibliográfica a respeito do tema representava um bônus para o acervo de inferências sobre o campo, mas não auxiliaria muito não fosse o estranhamento do "olhar crítico" da observação científica no campo - o que pode garantir inferências com mais qualidade sobre as descobertas.

Assim, o pesquisador adotou a etnografia para estranhar seu próprio campo e descobrir cientificamente o que se procede nele. De acordo com Bakan (1967, p. 144), "a tarefa da ciência é precisamente descobrir realidades que não são imediatamente evidentes". Aquelas a quem indagamos em entrevistas sobre a aprendizagem no universo do terreiro e no universo escolar foram escolhidas por representarem casos emblemáticos para nossa compreensão em torno da aprendizagem vivenciada no terreiro. Uma era a mais falante e de todas a única iniciada na religião, outra, a mais quieta, ainda aguardava a oportunidade de ser raspada (iniciada). Havia mais crianças no terreiro: um menino que não pôde ser entrevistado devido à hora em que chegou ao terreiro com sua mãe, prestes ao começo da cerimônia; outro que não quis ser entrevistado e algumas meninas que tinham ido poucas vezes lá acompanhadas de sua mãe.

Uma festa de candomblé no terreiro, o chamado toque, foi esperada para que as entrevistas fossem realizadas. E esta foi uma escolha influenciada por alguns fatores: no dia do toque haveria mais crianças de Candomblé no terreiro, tanto raspadas quanto dançantes ainda não raspadas, assim sendo estariam vestidas com suas roupas rituais, o que ao ver do pesquisador representa a restituição social, característica do grupo que influenciaria no modo como elas respondem a uma pergunta ou se portam numa conversa informal. A quantidade de tarefas ${ }^{2}$ nesse dia também ajudaria, pois seria menor - o que facilitaria ao pesquisador,

\footnotetext{
${ }^{2}$ A vivência de terreiro obrigava que os momentos de atividades internas rituais fossem aproveitados para
} observações e seus intervalos para conversas informais como os membros da comunidade religiosa. 
que é membro do terreiro, ganhar mais tempo sem atividades rituais para poder entrevistá-las.

As entrevistas foram iniciadas acreditando que a pesquisa com crianças é uma atividade que oferece um leque enorme de descobertas, possibilidades e aprendizados variados, como por exemplo, se posicionar com a curiosidade de uma criança para entender melhor o universo delas e o universo diante delas. Partir para a entrevista requeria do pesquisador uma postura de iniciando no universo da etnografia que, como todos os outros iniciandos, sentem-se abalados e frágeis no que será iniciado. A tentativa mais importante era neste momento se impor não mais como um filho-de-santo do terreiro, mas como um pesquisador distanciado daquela realidade e que estava interessado em fazer algumas entrevistas. Por se tratar de entrevistas a crianças, era necessário explicar a seus pais e responsáveis que os objetivos desta atividade era um procedimento ético realizado na pesquisa.

$\mathrm{O}$ pesquisador precisa ter a sensibilidade para entender os momentos ideais de se fazer certas perguntas. No caso de uma das entrevistadas, havia muito retraimento em falar sobre assuntos que envolviam a temática do racismo, justamente a entrevistada mais quieta, quando ela dava respostas muito curtas ou monossilábicas referentes a esta temática. Sugar informações nesse momento seria muito aproveitador e inoportuno, além do que a criança precisa de tempo de conhecimento sobre o que se passa consigo mesmo para dar exatidão de consciência sobre o que vai responder.

Nestes casos, o improviso citado por Graue e Walsh (2003, p. 127) deve se fazer muito presente, considerando as possibilidades de realização de atividades como jogos, desenhos, pinturas, dinâmicas, etc., para se obter os dados necessários sobre as temáticas difíceis de se trabalhar no campo, aproveitando momentos e inventando instrumentos e procedimentos para a recolha dos dados.

Entretanto, a entrevista foi encarada como um processo integrante da prática reflexiva, pois exige a descrição não induzida de relatos que serão analisados como dados. O momento da entrevista deve ser mais bem pensado, roteirizado para que não seja indutivo, e natural (o menos mecânico possível, aproveitando as deixas das falas dos entrevistados). Isto porque "se quisermos desperdiçar muito do nosso precioso tempo e o de toda a gente, é só ir para campo sem perguntas", pois "as perguntas são o motor da investigação" e "podem mudar depois de se estar no campo" mesmo traçando planos gerais para se aventurar tanto no conhecido quanto no desconhecido (GRAUE E WALSH, 2003, p. 116-117). A partir do aproveitamento das deixas das respostas dos 
entrevistados, podemos até fazer ganchos com os conceitos que elas apresentarem para novas perguntas a fim de que possam falar mais e à vontade.

Chegar até estas crianças pareceu tarefa fácil no quesito relacionamento pessoal. Entretanto, as barreiras físicas e temporais, como a distância geográfica antes da chegada de uma das crianças ao campo, com as quais o pesquisador deve desenvolver habilidades para lidar, estiveram tão presentes que um menino não pode ser entrevistado.

Por fim, as crianças sujeitos da pesquisa passavam segurança no momento da entrevista como realmente conhecedoras de sua realidade, que sabiam mais de seu universo que o pesquisador. Neste ponto, o respeito aos sujeitos das pesquisas é mantido, pois quem pesquisa com etnografia não pesquisa meros objetos, mas pesquisa com seres humanos objetificados, aos quais pertencem as falas respondidas na entrevista. Este cuidado coloca o entrevistador no lugar mais ético possível, tendo total ciência de que a autoridade pertence a quem fala. Tais cuidados podem evitar os excessos do pesquisador, o qual deve ser paciente e estar apto para lidar com possíveis conflitos de egos entre os entrevistados ou seus responsáveis num campo "atravessado por infinitas tensões e subjetividades" (CAPUTO, 2012, p. 185), especialmente por se tratar de crianças.

\section{O ENSINO RELIGIOSO}

Para compreender as nuances que envolvem o Ensino Religioso como prática escolarizada, também se fez necessário utilizar a etnografia como metodologia de pesquisa, já que ela possibilita um olhar de perto do objeto pesquisado e tem como preocupação os significados que os sujeitos atribuem às suas ações (GEERTZ, 1989).

Sendo o Ensino Religioso uma prática entrelaçada em inúmeras questões de ordens culturais e sociais, a sua compreensão implica em um reconhecimento (ou conhecimento) destas ordens, tornando-se necessário adotar uma metodologia que possibilite um contato mais próximo aos sujeitos que estão envolvidos nessa prática. Sendo esse um fator que nem sempre é visto com bons olhos pelos pesquisados, pois a presença do pesquisador traz certo receio aos sujeitos observados, isto pode contribuir para a artificialidade introduzida ao contexto pesquisado (PIREs, 2007).

A pesquisa realizada em uma escola da rede pública do município de Messias (AL) teve a duração de cinco meses, período no qual a pesquisadora acompanhava a professora duas vezes por semana durante todo o tempo das 
aulas de suas seis turmas da $4^{\mathrm{a}}$ e $5^{\mathrm{a}}$ etapas, sendo utilizado como instrumento de coleta de dados o diário de campo, entrevista e observação.

A pesquisadora foi solicitada pela professora de uma das turmas para que assumisse a aula. Essa participação foi fundamental para perceber o que seus alunos compreendiam como diversidade religiosa. Desse modo, a pesquisa etnográfica nos possibilitou uma visão mais ampla de como se dava a dinâmica do Ensino Religioso.

O método etnográfico traz grandes contribuições para se pensar o universo religioso, como também algumas limitações, muito embora seja uma característica de qualquer procedimento metodológico. Um dos limites dessa pesquisa refere-se ao fato de a pesquisadora ter ficado muito tempo com a professora, o que limitou o grau de interação entre ambas, já que o fato de estar sempre com a professora fazia com que a pesquisadora fosse vista também como professora. De certa forma, isso dificultava uma aproximação mais aberta com os sujeitos alunos.

A partir da etnografia foi possível compreender a perspectiva que assume o Ensino Religioso, dentro do âmbito escolar, e que reflete na maneira como ele é compreendido, afetando a importância atribuída a ele como área de conhecimento e fazendo-nos enxergar o universo no qual está inserido.

\section{O CONTEXTO DAS RELIGIÕES AFRO-BRASILEIRAS EM ALAGOAS}

Para compreendermos as singularidades envolvidas na relação entre a identidade religiosa afro-brasileira e o espaço escolar em Alagoas, devemos ter em mente os contextos histórico e social no qual esta discussão se situa. Em todo o Brasil, a questão das religiões afro-brasileiras é algo complexo, que se liga diretamente aos processos de dominação, conflito e resistência. Não à toa, mostra-se emblemático o fato de que houve uma "seleção" dos orixás a serem cultuados no Brasil, considerando o novo contexto social (BASTIDE, 1985), e nesse processo houve um intenso fluxo com a religião católica, por meio do chamado sincretismo ${ }^{3}$.

Apontando nesta direção, é importante ressaltar que, “[...] as ligações sincréticas do candomblé faziam-se essencialmente com o catolicismo popular, baseadas que estavam, ao nível das estruturas profundas, na equivalência entre o culto dos santos e o dos orixás" (MoTTA, 2000, p. 5), produzindo uma relação ambivalente da sociedade brasileira com os cultos afro-brasileiros (MAGGIE, 1992).

\footnotetext{
3 Para uma melhor análise dessa categoria vide os trabalhos de Sanchis (2001) e Ferretti (1995).
} 
Em Alagoas, as primeiras referências aos cultos afro-brasileiros remetem ao início do século XX, tanto por meio dos estudos do "folclore negro" quanto por jornais que, de modo tendencioso, apresentavam uma visão negativa $\mathrm{e}$ depreciativa desses cultos, os quais ficaram conhecidos no Estado por "Xangô" 4.

Ainda que, historicamente, Alagoas seja um Estado com uma forte presença negra em sua constituição, várias tensões estabeleceram-se no reconhecimento (e negação) dessa identidade e, certamente, a questão da religião entra aí como um importante elemento para compreender a formulação deste cenário. Um marco para sua compreensão foi o chamado "Quebra de Xangô", ou simplesmente “Quebra”, que ocorreu em fevereiro de 1912. Santos (2012, p. 191192) sintetiza o fato ocorrido da seguinte forma:

Em meio aos conflitos políticos pelo poder no período da República Velha entre o governador Euclides Malta e o grupo de oposição por seu sogro, Barão de Traipú, e pelo candidato Clodoaldo da Fonseca. Nas palavras de Ulisses Rafael, foi um dos "episódios mais violentos de que foram vítimas as casas de culto afrobrasileiro de Alagoas". Entre os dias 01 e 02 de fevereiro de 1912 a milícia particular conhecida como Liga dos Republicanos Combatentes, tumultuou a cidade. Prepararam-se, invadiram e quebraram os principais terreiros de Xangô em Maceió. Além de várias outras ações violentas, Tia Marcelina, africana, conhecida Ialorixá da época, foi morta com um golpe de sabre na cabeça. Muitos outros pais e mães de santo e membros do culto sofreram violência e humilhação. Tiveram suas casas invadidas, os assentamentos de orixás e objetos rituais quebrados ou queimados. Tal fato foi justificado perante a população através de campanha feita pelos jornais de oposição, em que associava a pessoa de Euclides Malta com os terreiros de Xangô. Dizia-se que Malta era frequentador de terreiros, xangozeiro, filho de Leba - designativo de origem jeje correspondente ao orixá nagô Exu. Dessa forma, por estar supostamente o governador envolvido com "bruxarias demoníacas", explicavam-se todos os problemas sociais e econômicos do Estado.

Notoriamente, este ocorrido produz um verdadeiro "trauma cultural" 5, impactando negativamente a realidade dos cultos nessa região. Segundo Rafael (2010, p. 307):

Depois do ocorrido, os atabaques foram silenciados. Já não se tinha mais notícias do seu uso em qualquer tipo de manifestação, aliás, eles também estiveram ausentes na exposição realizada na rua do Sopapo. Nunca mais se teve notícias da presença de maracatus nos Carnavais de Maceió; seus mestres, confundidos não sem razão, com os babalorixás dos terreiros perseguidos, já não se encontravam na cidade. A grande maioria buscou refúgio nos estados vizinhos e até em locais

\footnotetext{
4 Esta denominação utilizada para se referir aos cultos afro-brasileiros de maneira geral é amplamente utilizada em Alagoas e Pernambuco (RIBEIRO, 1982).

5 Alexander (2004, p. 1) aponta que "trauma cultural ocorre quando os membros de uma coletividade sentem que foram submetidos a um evento horrendo que deixa marcas indeléveis em sua consciência de grupo, marcando suas memórias para sempre e mudando sua identidade futura em aspectos fundamentais e irrevogáveis" (tradução do autor).
} 
mais distantes, como a Bahia e o Rio de Janeiro. As manifestações populares integradas por negros passaram a ser vistas com certa desconfiança, principalmente os xangôs, os quais continuaram a ser desenvolvidos pelos poucos remanescentes daquelas antigas casas que permaneceram na capital estadual, temendo mais as punições dos orixás do que as das autoridades policiais.

A "Operação Xangô" atingiu de forma marcante os cultos afro-brasileiros em Alagoas, mas não de modo definitivo. Poucos meses depois desse episódio, mais especificamente no dia 4 de agosto do respectivo ano, o mesmo jornal que narrou o "Quebra", noticiou a existência de um terreiro lá para as bandas do Trapiche da Barra, uma das áreas mais afastadas da cidade realizando cerimônias religiosas, embora sem o aparato de tempos passados.

Assim é que, anos mais tarde, Gonçalves Fernandes, o estudioso pernambucano, localizaria em visita aos terreiros alagoanos, mais especificamente à casa do babalorixá "Padre Nosso", essa modalidade exclusiva de culto, o "xangô-rezadobaixo", descrita no primeiro capítulo do referido livro, O Sincretismo no Brasil, como uma liturgia fechada, sem danças, cantos e sem a exaltação dos toques dos tambores. As cerimônias de então estava cercadas de mistério e segredo, prevalecendo o cochicho e as atitudes pouco extravagantes que concorreram para o episódio do "Quebra" com uma das particularidades que cercam o episódio.

Foi esse o modelo de culto que durante anos predominou na capital de Alagoas.

Tendo em vista a magnitude do episódio aqui brevemente narrado ${ }^{6}$, afirmamos que é impossível compreender a dinâmica da identidade religiosa afro-brasileira em Alagoas, tanto na escola como em outros espaços, sem ter em mente tais questões. $\mathrm{O}$ violento processo vivenciado no começo do século $\mathrm{XX}$ emoldura os dilemas da identidade religiosa no Estado.

A escola pensada como um lócus onde ocorre o cruzamento de culturas e identidades, sendo não apenas um espaço de socialização, mas também de sociabilidades (GUSMÃO, 2003), sintetiza os dilemas culturais do contexto social no qual se insere, pois não é possível compreender o "mundo da escola" apartado do "mundo da cultura", tendo em vista que toda prática educativa é essencialmente cultural.

O episódio do "Quebra" afetou de forma mais incisiva os cultos afrobrasileiros em Alagoas, mas não apenas estes - tendo em vista que a identidade cultural é sempre relacional (WOODWARD, 2009) e que, portanto, a compreensão em torno do "eu" está intimamente relacionada com a do "outro". Podemos afirmar, partindo desta perspectiva, que o "Quebra" alterou a forma de se pensar as religiões como um todo e a maneira de interpretar os diálogos possíveis entre as diversas matrizes religiosas em Alagoas. Ainda concernente ao impacto do "Quebra” sobre o Xangô em Alagoas, Rogério (2008, p. 34-35) aponta que:

${ }^{6}$ Para uma melhor análise do "Quebra”, vide Rafael (2012). 
Na verdade, tendo à vista um quadro parcial, mas aproximado, da grande concentração de casas religiosas de tradição afro-brasileira na cidade, hoje observamos que, mesmo com toda repressão vivenciada, essas referências não desapareceram da memória e da vida da população. A junção das várias nações ao próprio processo de transformação das culturas negras, que tiveram que "substituir" seus padrões culturais tradicionais em meio a uma outra sociedade, tendo esta difundida no âmbito das populações negras seus aspectos culturais característicos, fez com que ocorresse, em consequência, o empréstimo "direto" de traços culturais característicos de um grupo para o outro. Em Maceió, os terreiros, mesmo reproduzindo o modelo "nagô", se distanciam do chamado modelo "nagô puro", criado como categoria analítica por pesquisadores. Talvez o quebra-quebra das antigas casas de cultos tenha impossibilitado a identificação, ou mesmo a caracterização de uma única "nação" predominante nos anos seguintes. Sabe-se, contudo, que por volta dos anos cinquenta, os Candomblés reaparecem agora traçados com a Umbanda.

Portanto, na cidade de Maceió, é significativo o número de terreiros de outras linhas/nações não tão próximas do modelo "puro". Até mesmo os terreiros ditos "tradicionais", aos poucos se mostram ligados à diversidade de práticas rituais de outras nações que não o nagô. É importante lembrar que, em face do quebraquebra, o problema da história da religiosidade afro-brasileira em Alagoas, especialmente em Maceió, adquiriu caráter particular. De modo geral, Maceió reconstruiu seus terreiros a partir de circunstâncias específicas, vendo-se como uma cultura perseguida e "controlada". Neste contexto, as expressões religiosas afro-brasileiras mudaram suas práticas e seus fundamentos para adaptarem-se às novas condições sociais.

O que podemos perceber é que, apesar da substancial presença de terreiros na cidade de Maceió (CAVALCANTI; RogÉRIO, 2008), a identidade negra ainda é fortemente negada, invisibilizada. Em certa medida, esse fenômeno pode ser explicado, em conjunto a outros fatores, pela presença do "Quebra” na memória coletiva dos praticantes de Xangô em Alagoas.

Esse processo de invisibilização da identidade religiosa afro-brasileira tornase ainda mais patente no espaço escolar, considerando o modelo conservador ainda em curso, que tende a pensar os sujeitos que animam a prática escolar de forma homogeneizada, em especial os alunos, pois, como indica Sarmento (2011), no espaço escolar a criança desaparece ante a escola, restando-lhe apenas o aluno, destituído de toda a sua bagagem cultural. Passemos então para uma análise acerca da relação entre as religiões afro-brasileiras e a escola.

\section{O XANGÔ E A ESCOLA}

Apesar de oficialmente se estabelecer a separação entre Igreja e Estado no Brasil com o advento da República, tornando-se a Escola um espaço laico - o que é reafirmado em toda a legislação educacional mais recente, em especial na 
atual Lei de Diretrizes e Bases da Educação - LDB (lei no 9.394/96) -, o que observamos é um cenário cambaleante e heterogêneo, com substanciais diferenças regionais. Estes fatores podem ser sentidos principalmente por meio das polêmicas vivenciadas em torno do Ensino Religioso nas diversas unidades da Federação.

Como a regulamentação do que é lecionado fica ao encargo das Secretarias Estaduais e Municipais de Educação, temos um cenário bastante diverso no Brasil, no qual alguns Estados adotam o modelo "confessional”, em que os alunos são divididos de acordo com o credo nessas aulas, ou ainda "supraconfessional”, "interconfessional” ou "não-confessional” (GIUMBELLI, 2009).

Fora a própria questão do Ensino Religioso, há de se reconhecer que a escola não é culturalmente neutra (MACEDO, 2010), o que possui sérias implicações em torno de quais identidades serão reafirmadas neste espaço e quais serão invizibilizadas, negadas, rechaçadas.

Pesquisas como as de Caputo (2012), apontam para a tensão que se estabelece no caso específico dos alunos que pertencem às religiões afrobrasileiras na escola, especialmente no caso das aulas de Ensino Religioso. Isto se substancia não apenas nas práticas docentes, mas também na necessidade que os alunos sentem de esconder o seu credo com receio da discriminação, existente também em alguns livros didáticos.

$\mathrm{Na}$ pesquisa etnográfica que realizamos junto a uma turma de Ensino Religioso, em uma escola na rede municipal de ensino na cidade de Messias, encontramos um claro direcionamento das aulas para a religião da professora, o Catolicismo, que era afirmado não apenas por meio dos conteúdos a serem discutidos, mas também das práticas e ações realizadas em sala de aula, ainda que a proposta da Secretaria de Educação do Município siga, teoricamente, o referencial curricular estadual, que em princípio valoriza a questão da diversidade religiosa. Segundo o documento:

A diversidade religiosa é outro tema da diversidade, sendo papel das escolas o respeito a todas as formas de expressão e de representação das diversas religiosidades, sejam elas matrizes religiosas europeias, africanas, asiáticas, indígenas, orientais, dentre outras. É o reconhecimento e autoafirmação dos sujeitos e do direito de liberdade de expressão de suas crenças e rituais religiosos. Portanto, as práticas pedagógicas devem combater todo tipo de intolerância religiosa. (ALAGOAS, 2010, p. 31)

Contudo, o que verificamos na prática, após um semestre de observação, é que a diversidade é silenciada, resumindo-se muitas vezes à diversidade dentro do próprio Cristianismo e, como coloca Pierucci (2006), nossa diversidade 
religiosa ainda é balbuciante. Neste sentido, é sintomática a fala de uma das alunas entrevistadas: "É uma das minhas preferidas porque fala da minha religião, fala das outras, mas principalmente da minha, traz muito conhecimento e eu acho muito importante."

$\mathrm{O}$ aluno que pertence à religião tida como predominante passa a se enxergar naquelas aulas, mas, se por um lado, devemos reconhecer que a realidade em sala de aula é essencialmente heterogênea, por outro, mesmo se tratando de uma turma apenas de alunos católicos, conhecer as religiões afro-brasileiras, assim como o Espiritismo, o Protestantismo etc., possui uma relevância que vai para além da filiação religiosa dos alunos. Esta proposta implica em conhecer a formação cultural e social do Brasil. Como indica Prandi (2005, p. 159):

A cultura africana diluída na formação da cultura brasileira corresponde a um vasto elenco de itens que abrangem a língua, a culinária, a música e artes diversas, além de valores sociais, representações místicas e concepções religiosas, conservadas não a partir de uma matriz africana única, mas de várias, oriundas de diferentes povos africanos. Fora do campo religioso, nenhuma das instituições culturais africanas logrou, entretanto, sobreviver com suas estruturas próprias.

A questão da cultura africana, nesse caso das religiões afro-brasileiras, e seu debate no espaço escolar estão longe de ser uma questão que diga respeito exclusivamente aos afro-descendentes ou praticantes das religiões afrobrasileiras, negros ou não, pois nos remete a uma compreensão mais profunda sobre a nossa própria sociedade. É por essa razão que Gusmão (2012, p. 105) aponta que a lei $\mathrm{n}^{0}$ 10.639/03 7 :

[...] carrega no seu processo um dado catalisador que é a dinâmica de mexer com a escola. Isso ela faz. Faz com que todos os agentes da escola repensem a sua prática. Não só a escola pública, ou só a escola privada, ou só a escola confessional, aquela que tem um grande contingente de negros ou não, mas toda escola. Ela obriga a que se comece a pensar quem é o cidadão brasileiro e qual a sua participação numa sociedade de inclusão. Pensar o negro é, apenas, a ponta do iceberg para se pensar em todos os brasileiros que vivem alguma forma de exclusão como cidadãos deste país. É por em movimento mecanismos e ações que permitam aos diferentes grupos fugir aos estereótipos e à homogeneização a que são submetidos, para poder dizer com suas particularidades e no conjunto das particularidades existentes no Brasil, de uma sociedade melhor.

Mas, obviamente, quando nos referimos à realidade daqueles que têm suas identidades negadas no espaço escolar, a questão assume outros contornos.

\footnotetext{
7 Apesar do avanço da legislação educacional, com destaque para a lei $n^{0}$ 10.639/o3, que institui a obrigatoriedade do ensino de história e cultura afro-brasileiras na escola, ainda há inúmeros impasses em sua implementação, que vão desde o despreparo e preconceito de muitos professores, até a resistência presente em determinados grupos sociais em discutir tais questões, envolvendo alunos, pais e gestores escolares. Para uma melhor análise dessa questão vide Gomes (2009).
} 
Ainda durante o processo de observação, houve uma oportunidade em que se buscou discutir a questão da diversidade, propulsionada pela pesquisadora em campo, que se viu na situação de ter que assumir a turma por indicação da professora. Num certo momento, um dos alunos demonstrou conhecimento das religiões afro-brasileiras, afirmando que muito do que era dito originava-se do desconhecimento existente, o que foi suficiente para despertar risos por parte de alguns alunos ${ }^{8}$.

Durante a discussão do assunto, foi possível perceber a compreensão da turma sobre a diversidade religiosa, o que se constituía em uma problemática, já que a diversidade era vista apenas em relação às religiões católica e protestantes. Desse modo, foi necessário apontar questões relacionadas a conhecimentos referentes às religiões afro-brasileiras e, ao tratar do assunto, era perceptível nas falas e faces dos outros alunos o preconceito e a discriminação que eles tinham sobre essas religiões. Por exemplo, ao nos referirmos a alguma entidade das religiões afro-brasileiras, eram ouvidas frases do tipo: "misericórdia, isso é coisa do diabo!". No entanto, um aluno, sempre que alguém depreciava elementos de sua religião, se incomodava e a defendia, sendo novamente motivo de risadas e brincadeiras por parte de outros alunos que eram praticantes da religião católica, evangélica e até ex-praticantes de Candomblé.

A posição assumida por esse aluno chamou a atenção para os percursos da pesquisa, visto que, durante o período dela, nenhum dos alunos entrevistados se declarou como praticante de religiões afro-brasileiras, inclusive aquele que a defendeu. No entanto, em uma conversa informal depois da aula, ele afirmou ser praticante de Candomblé, o que denota a dificuldade de assumir a sua identidade religiosa no espaço público. Um dos fatores que podem contribuir para essa omissão refere-se ao silenciamento que a escola faz diante dessa temática, o que serve para reafirmar as concepções negativas que se tem a respeito da diversidade religiosa.

Na situação de entrevista, o referido aluno disse o seguinte a respeito das aulas de Ensino Religioso:

Não contribui para a sua formação, pois quando vão falar de religião é sobre a igreja católica, evangélica, nunca falam da minha religião que é o Candomblé, e quando falam, é de mal, por isso que não me interessa. Essa religião deve ser falada nas aulas, por que não só eu, como outras pessoas participam dessa religião e muitos não sabem o que significa e só querem dizer que só fazem o mal.

${ }^{8}$ Outros o denominavam "macumbeiro". 
Bakke (2011), em sua pesquisa, apontou que, via de regra, os livros didáticos, aqueles utilizados mais recorrentemente em sala de aula, apresentam o debate em torno das religiões afro-brasileiras de forma mais superficial, se comparados aos paradidáticos, que normalmente se restringem às bibliotecas.

No único caso em que a pesquisadora observou um cenário distinto durante seu trabalho de campo, ao trabalhar de forma mais detalhada esta questão em sala de aula, houve protestos por parte daqueles que se disseram desrespeitados pela menção às religiões afro-brasileiras no espaço escolar. Ao examinarmos diversas pesquisas sobre o tema, pareceu-nos ser uma realidade nacional o elemento da intolerância religiosa, ainda que haja particularidades nos diversos cenários 9 .

Apesar desse cenário, marcado por uma intensa violência simbólica nos campos religioso e escolar, ao entrevistarmos duas crianças candomblecistas em Maceió, de 9 e 12 anos de idade, que frequentam o terceiro e o sexto anos do ensino fundamental respectivamente, encontramos uma valorização do espaço escolar. Uma das crianças de Candomblé, entrevistadas no terreiro, disse em entrevista: “Ah, a escola é o meu futuro melhor. Meu sonho é ser médica, então meu pai disse que siga a escola que um dia eu posso chegar lá”. Esse reconhecimento da importância dos estudos, que remete principalmente a um projeto de futuro, ainda que o preconceito apareça como elemento negativo da mesma forma nas vivências escolares, ressalta também o silêncio dos professores sobre a questão; pois, ao passo que esta criança dizia isto, a outra entrevistada mencionava que nenhum de seus professores fazia algo para combater o preconceito que ela vinha sofrendo na escola (no caso, a criança chamava de "tomar providência").

Chamou-nos ainda atenção a intensa aprendizagem que ocorre no terreiro, no tocante ao universo ritualístico, incluindo palavras e cantigas próprias dos cultos afro-brasileiros, utilização de ervas, manipulação de animais, conhecimento sobre o panteão dos cultos, aprendizados sobre a vida social, etc.

Notoriamente, a escola olvida as diversas formas de conhecimento e reduz a pluralidade de saberes dos quais os alunos são portadores para focar nos conhecimentos escolares dos quais eles seriam "destituídos". Neste sentido, são elucidativas as críticas realizadas por Santos (2008) ao que ele denomina de Razão Metonímica, que nortearia o pensamento das sociedades modernas ocidentais. Segundo este autor, esta forma de razão estaria baseada no desperdício da experiência social.

\footnotetext{
9 Para além da intolerância religiosa, Silva (2007, p. 219) aponta que os "símbolos da herança africana no Brasil, mesmo que não sejam exatamente religiosos, mas de alguma forma aludam às religiões afrobrasileiras, são estigmatizados e combatidos".
} 
Santos (2007) ainda argumenta que a Razão Metonímica produz cinco monoculturas: a primeira seria a do saber e do rigor: "[...] a ideia de que o único saber rigoroso é o saber científico; portanto, outros conhecimentos não têm validade nem o rigor do conhecimento científico" (p. 29); a segunda seria a do tempo linear: "[...] a ideia de que a história tem um sentido, uma direção, e de que os países desenvolvidos estão na dianteira” (p. 29); a terceira é a da naturalização das diferenças que "ao contrário da relação capital/trabalho, aqui a hierarquia não é causa da diferença mas sua consequência, porque os que são inferiores nessas classificações naturais os são 'por natureza'” (p. 30); a quarta é da escala dominante, que se assenta na ideia de que há uma escala dominante nas coisas, que se apresentam historicamente na tradição ocidental, tanto através do universalismo quanto, mais recentemente, da globalização. Nesta perspectiva, "o global e universal é hegemônico; o particular e local não conta, é invisível, descartável, desprezível” ; por fim, haveria a monocultura do produtivismo capitalista: "é a ideia de que o crescimento econômico e a produtividade mensurada em um ciclo de produção determinam e produtividade do trabalho humano ou da natureza, e tudo mais não conta” (p. 31).

O que nos parece é que a escola está assentada justamente nessa forma de Razão, sendo que, considerando-se o processo histórico e as configurações sociais próprias de cada sociedade, algumas experiências são mais rechaçadas que outras, e esse é o caso da experiência social presente nas religiões afrobrasileiras, em especial em Alagoas, onde ocorreu um substancial trauma cultural, o já mencionado "Quebra”.

Entretanto, não se trata aqui de tomar esta realidade como dada e estanque, pois da mesma forma que Santos $(2007,2008)$ propõe uma ecologia de saberes em substituição às monoculturas produzidas, acreditamos que a sala de aula pode ser um importante espaço para a produção de tais ecologias. A escola deve ser compreendida como um espaço de produção sociocultural, e seus professores como mediadores culturais (OLIVEIRA, 2012), que potencialmente podem impactar a realidade de seus alunos por meio de suas práticas pedagógicas, como já citado por uma das crianças: "[...] eu acho que isso nunca vai acabar se ninguém tomar uma providência” ${ }^{10}$.

\section{CONSIDERAÇÕES FINAIS}

A reflexão em torno da identidade religiosa afro-brasileira na escola nos remete a uma série de questões mais amplas. Primeiramente, ao nos remetermos à

${ }^{10}$ Criança entrevistada no dia 30 de junho de 2013. 
realidade de Alagoas, é-nos evidente que o trauma cultural aqui existente relacionese diretamente com a invisibilização desta identidade no espaço escolar, o que se aprofunda mediante os profundos problemas educacionais existentes - ainda que não seja condição suficiente. Entretanto, a existência de professores bem formados, conhecedores da história e da cultura afro-brasileiras, é consideração sine qua non para pensarmos a escola como lócus da superação do preconceito.

Outra questão importante, é que ao pensarmos a relação entre as religiões afro-brasileiras e a escola, somos instigados a refletir sobre que modelo de sociedade é apresentado na educação formal brasileira e quais as implicações para os alunos ao se deparar com este. Ao mesmo tempo devemos ir além, cabenos questionar quais outros modelos de sociedade são possíveis e quais projetos estão em disputa. Os avanços dos mecanismos legais, por meio da lei $\mathrm{n}^{\mathrm{o}}$ 10.639/o3 e da criação da Secretaria de Educação Continuada, Alfabetização e Diversidade - SECADI em 2004 indicam novas possibilidades para pensar o lugar da escola ante aos dilemas culturais de nossa sociedade.

Por fim, devemos reconhecer que há uma série de mudanças em curso, que se atrelam às questões que vêm sendo suscitadas pelos Movimentos Negros, bem como às alterações vivenciadas na sociedade brasileira como um todo nas últimas décadas - o que tem alterado a realidade das religiões afro-brasileiras, principalmente por meio da "desetnização", no sentido destas se tornarem cada vez mais religiões universais, e da "reafricanização" dos cultos (PRANDI, 2004).

Encarar que a religião está em processo contínuo de transformações nos possibilita vislumbrar também que o seu lugar está sempre em mudança e que, portanto, a forma como as religiões afro-brasileiras são percebidas pela escola tende a se modificar, mesmo que o processo de invisibilização seja ainda patente. A escola continua demasiadamente conservadora e monocultural, todavia, o que tem ocorrido na sociedade brasileira nas últimas décadas nos levar a crer que apesar de contraditório e não linear, percorremos um caminho rumo a uma ampliação dos horizontes culturais existentes na educação formal para as crianças e jovens das religiões afro-brasileiras em Alagoas.

\section{REFERÊNCIAS}

\section{ALAGOAS. Referencial Curricular da Educação Básica para as Escolas Públicas de Alagoas. Maceió, 2010.}

ALEXANDER, J. Toward to Theory of Cultural Trauma. In: ALEXANDER Jeffrey et al. (Orgs.) Cultural Trauma and Collective Identity. Berkeley: University of California Press, 2004. p. 1-31. 
BAKAN, D. On method: toward a reconstruction of psychological investigation. San Francisco: Jossey-Bass, 1967.

BAKKE, R. R. B. Na escola com os orixá: o ensino das religiões afro-brasileiras na aplicação da lei 10.639. 2011. Tese (Doutorado em Antropologia) - Faculdade de Filosofia, Letras e Ciências Humanas. Universidade de São Paulo, São Paulo, 2011.

BASTIDE, R. As religiões africanas no Brasil. São Paulo: Pioneira, 1985. v. 2

BRASIL. Lei $\mathrm{n}^{\circ}$ 9.394, de 20 de dezembro de 1996. Estabelece as diretrizes e bases da educação nacional. Diário Oficial da União, Brasília, 21 de dezembro de 1996.

. Lei $\mathrm{n}^{0} 10.639$ de 9 de janeiro de 2003. Altera a Lei no 9.394, de 20 de dezembro de 1996, que estabelece as diretrizes e bases da educação nacional, para incluir no currículo oficial da Rede de Ensino a obrigatoriedade da temática "História e Cultura Afro-Brasileira", e dá outras providências. Diário Oficial da União, Brasília, 10 de janeiro 2003.

BOURDIEU, P.; PASSERON, J. A Reprodução. Petrópolis, RJ: Vozes, 2008.

CANDAU, V. M. F.; MOREIRA, A. F. B. Educação Escolar e Cultura(s):construindo caminhos. Revista Brasileira de Educação, Brasil, s/v, n.23, p. 156-168, 2003.

CAPUTO, S. G.. Educação em terreiros - e como a escola se relaciona com crianças de candomblé. Rio de Janeiro: Pallas, 2012.

CAVALCANTI, B. C.; ROGÉRIO, J. P.. Mapeando o Xangô - notas sobre mobilidade espacial e dinâmica simbólica nos terreiros afro-brasileiros de Maceió. In: BARROS, Rachel Rocha de Almeida; CAVALCANTI, Bruno César; SUASSUNA, Clara. (Orgs.). Religiões Afro-brasileiras. Maceió: EDUFAL, 2008, p. 1-19.

DAMATTA, R. O ofício de etnólogo, ou como ter "Anthropological Blues". In: NUNES, E. A aventura sociológica: objetividade, paixão, improviso e método na pesquisa social. Rio de Janeiro: Zahar, 1978, p. 23-35.

FERRETTI, S. F. Repensando o Sincretismo. São Paulo/São Luís:

EDUSP/FAPEMA, 1995.

FREITAS, M. C.r. Alunos rústicos, arcaicos \& primitivos: o pensamento social no campo da educação. São Paulo: Cortez Editora, 2005.

GEERTZ, C. A interpretação das culturas. Rio de Janeiro: LTC, 1989.

GIUMBELLI, E.. Ensino Religioso em Escolas Públicas no Brasil: notas de pesquisa. Debates do NER, v. 14, p. 50-68, 2009.

GOMES, N. L.. Limites e possibilidades da implementação da Lei 10.639/2003 no contexto das políticas públicas em educação. In: PAULA, M; HERINGER, R. (Orgs.) Caminhos emergentes: estado e sociedade na superação das desigualdades raciais no Brasil. Rio de Janeiro: Fundação Heinrich Boll, ActionAid, 2009. p. 39-74.

GRAUE M. E.; WALSH D. J. Investigação etnográfica com crianças: teorias, métodos e ética. Lisboa: Fundação Calouste Gulbenkian, 2003. 
GUSMÃO, N. M. de. Africanidades e Brasilidades: desafio da formação docente.

REALIS - Revista de Estudos Antiutilitaristas e Poscoloniais, v. 2, ${ }^{0}$ 1, p. 93108, 2012.

Os Desafios da Diversidade na Escola. In: GUSMÃO, N. M. M. Diversidade, Cultura e Educação: Olhares Cruzados. São Paulo: Biruta, 2003. p. 83-105.

HALL, S. Da Diáspora. Belo Horizonte: EDUFMG, 2009.

MACEDO, E. A Cultura e a Escola. In: MISKOLCI, Richard (Org.). Marcas da Diferença no Ensino Escolar. São Carlos: EdUFSCar, 2010. p. 11-44.

MAGGIE, Y. Medo de Feitiço: Relações entre a Magia e o Poder no Brasil. Rio de Janeiro: Arquivo Nacional, 1992.

MOTTA, R.. Tempo e Milênio nas Religiões Afro-Brasileiras. In: XXIV ENCONTRO ANUAL da ANPOCS. Caxambu: Encontro Anual da ANPOCS, 2000.

OLIVEIRA, A.. O Educador e Sua Magia. Educação on-Line, s/v, n 9, p. 1-17, 2012.

PIERUCCI, A. F.. Cadê nossa diversidade religiosa? In: TEXEIRA, Faustino; MENEZES, Renata. (Org.). As religiões no Brasil: Continuidades e rupturas. Petrópolis: Vozes, 2006. p. 49-53.

PETITAT, A. Produção da Escola/Produção da Sociedade. Petrópolis: Vozes, 1994.

PIRES, Flávia F. Ser adulta e pesquisar crianças: explorando possibilidades metodológicas na pesquisa antropológica. Revista de Antropologia, v. 50, n. 1, p. 225-270, 2007.

PRANDI, R.. O Brasil com axé: candomblé e umbanda no mercado religioso. Estudos Avançados, v. 18, n. 52, p. 51-66, 2004.

Segredos Guardados. São Paulo: Companhia das Letras, 2005.

RAFAEL, U. N.. Muito barulho por nada ou o "xangô rezado baixo": uma etnografia do "quebra de 1912" em Alagoas, Brasil. Etnográfica, v. 14, n. 2, p. 289-310, 2010.

Xangô rezado baixo: religião e política na Primeira República. São

Cristóvão: Editora da Universidade Federal de Sergipe/Maceió: Editora da Universidade Federal de Alagoas, 2012.

RIBEIRO, R. Antropologia da Religião e outros Estudos. Recife: Editora Massangana, 1982.

ROGÉRIO, J. P.. Se não há Sacrifício, não há Religião. Se não há sangue, não há Xangô: um estudo do sacrifício no Palácio de Iemanjá. 2008. Dissertação (Mestrado em Antropologia) - Centro de Filosofia e Ciências Humanas. Universidade Federal de Pernambuco, Recife, 2008. 
SANCHIS, P.. Religiões, religião... Alguns problemas do sincretismo no campo religioso brasileiro. In: SANCHIS, P. (Org.) Fiéis e cidadãos: Percursos do sincretismo no Brasil. Rio de Janeiro: EdUERJ, 2001, p. 9-58.

SANTOS, B. de S. A Crítica da Razão Indolente: contra o desperdício da experiência. São Paulo: Cortez, 2009. Cortez, 2008.

A Gramática do Tempo: para uma nova cultura política. São Paulo:

SANTOS, I. M. F. dos. "Nos domínios de Exu e Xangô o Axé Nunca se Quebra". Transformações Históricas nas Religiões Afro-Brasileiras em São Paulo e Maceió: 19702000. 2012. Tese (Doutorado em História Social) - Faculdade de Filosofia, Letras e Ciências Humanas. Universidade de São Paulo, São Paulo, 2012.

SARMento, M. A Reinvenção do Ofício de Criança e de Aluno. Atos de Pesquisa em Educação, v. 6, n. 3, p. 581-602, 2011.

SILVA, V. G. da. Neopentecostalismo e religiões afro-brasileiras: Significados do ataque aos símbolos da herança religiosa africana no Brasil contemporâneo. Mana, v. 13 , n 1, p. 207-236, 2007.

WOODWARD, K.. Identidade e diferença: uma introdução teórica e conceitual. In: SILVA, Tomaz Tadeu (Org.). Identidade e Diferença: as perspectivas dos estudos culturais. Petrópolis, RJ: Vozes, 2009. p. 7-77. 